\title{
Conformation of $\mathrm{Cyclo}(\mathrm{L}-\mathrm{Ser}(\mathrm{O}-\mathrm{Bzl})-\mathrm{D}-\mathrm{Leu}-\mathrm{L}-\mathrm{His})_{2}$ and Cyclo(L-Ser-D-Leu-L-His $)_{2}$ in Solution
}

\author{
Masato KodaKa,* Toru ShImizU, and Masahiro HATANo \\ Chemical Research Institute of Non-aqueous Solutions, \\ Tohoku University, Sendai 980, Japan \\ *National Chemical Laboratory for Industry, Tsukuba 305, Japan
}

(Received October 6, 1983)

\begin{abstract}
Proton NMR spectra of cyclic hexapeptides, cyclo(L-Ser( $O$-Bzl)-D-Leu-L-His $)_{2}$ and $\operatorname{cyclo}(\mathrm{L}-\mathrm{Ser}-\mathrm{D}-\mathrm{Leu}-\mathrm{L}-\mathrm{His})_{2}$, were measured and analyzed to study their solution conformation. The histidyl imidazolyl planes were found to have a tendency to face predominantly toward the adjacent $\mathrm{D}$-leucyl side chains. It was also confirmed that the cyclic peptides are very likely to have Type II' $\beta$-turns in the D-Leu-L-His sequence.

KEY WORDS Solution Conformation / Cyclic Hexapeptide / ${ }^{1} \mathrm{H}$ NMR Spectroscopy /
\end{abstract}

Attention has been directed to cyclic oligopeptides as enzyme models, since the movement of their main chains is restricted and the side chains are also likely to be fixed in specific spatial positions, which is characteristic of the active sites of enzymes. Sheehan et al. ${ }^{1}$ and Kopple et al..$^{2,3}$ investigated several cyclic hexapeptides containing histidyl residues as hydrolytic enzyme models. However, these cyclic hexapeptides have glycyl residues so that the main chains still have some degree of freedom. The segmental movement of the main chains prevents specific orientation of the side chains. Imanishi et al. studied cyclic dipeptide, cyclo(D-Leu-L-His), and found that this cyclic dipeptide significantly catalyzes the hydrolysis of $p$-nitrophenyl laurate. ${ }^{4,5}$ However, the diastereomer, cyclo(L-Leu-LHis), does not catalyze the hydrolysis. These findings suggest that the spatial orientation of the side chains is very important for the occurrence of catalytic activity. The orientation of the histidyl imidazole in $\operatorname{cyclo}$ (DLeu-L-His) has proved suitable for nucleophilic attack on the carbonyl group of the substrate.
In the previous study, $c y c l o(\mathrm{~L}-\mathrm{Cys}(S-\mathrm{Acm})-$ D-Leu-L-His) $)_{2}$ (1) was found to have two $\beta$ turns at the D-Leu-L-His sequences the histidyl imidazolyl plane likely to be oriented toward the adjacent D-leucyl side chain. ${ }^{6}$ The mainchain conformation of 1 seems rigid, owing partly to the formation of $\beta$-turns and the steric hindrance caused by the large side chains. This conformational rigidity may be responsible for the specific orientation of the histidyl side chain. Generally in cyclic hexapeptides, the orientation of side chains are more widely distributed, ${ }^{7}$ in striking contrast with the results for 1 . In the present study, we have made a more detailed investigation of the conformation of analogous cyclic hexapeptides, $\operatorname{cyclo}\left(\mathrm{L}-\mathrm{Ser}(O \text {-Bzl)-D-Leu-L-His })_{2}\right.$ (2) and cyclo(L-Ser-D-Leu-L-His) $)_{2}$ (3). The cyclic peptide, cyclo(L-Ser(O-Bzl)-Gly-L-His $)_{2}$ (4), was also studied for comparison. The results show that $\mathbf{2}$ and $\mathbf{3}$ also have $\beta$-turns at D-LeuL-His sequences and that their histidyl side chains also face predominantly toward those of the adjacent D-leucyl. 


\section{EXPERIMENTAL}

\section{Materials}

Cyclic peptides $\mathbf{2}$ and $\mathbf{4}$ were synthesized in a manner similar to that for $1 .^{8}$ Following purification, they showed a single spot (Pauly test, positive; ninhydrin test, negative) on silica gel TLC in $n-\mathrm{BuOH}-\mathrm{AcOH}-\mathrm{H}_{2} \mathrm{O}$ (4: $1: 2$ in vol. $)$. Amino acid analysis: Ser: Leu : His = $1.0: 0.9: 0.9$, Ser: Gly $:$ His $=1.0: 0.9: 1.1$. To remove the benzyl group from the $O$-benzyl-Lseryl residue in 2 , it was dissolved in $25 \%$ anhydrous $\mathrm{HBr} / \mathrm{AcOH}$ at room temperature for $1 \mathrm{~h}^{9}{ }^{9}$ After the solvent was evaporated under reduced pressure, the residue was treated with $\mathrm{NaOCH}_{3} / \mathrm{CH}_{3} \mathrm{OH}$ solution to remove acetyl groups from the partially acetylated seryl residue. ${ }^{10}$ Following evaporation of the solvent, the residue was purified by preparative TLC and a Sephadex LH-20 column, as in the case of $1 .^{8}$ The purified peptide 3 showed a single spot (Pauly test, positive; ninhydrin test, negative) on silica gel TLC in $n-\mathrm{BuOH}-$ $\mathrm{AcOH}-\mathrm{H}_{2} \mathrm{O}$ (4:1:2 in vol.). Amino acid analysis: Ser : Leu : His = $1.0: 1.0: 0.9$.

$\mathrm{D}_{2} \mathrm{O}$ was obtained from Commissariat à L'Energie Atomique of France, and dimethyl$d_{6}$ sulfoxide (DMSO- $d_{6}$ ) from E. Merck, Japan. Other reagents were of the highest grade available.

\section{Methods}

Proton NMR spectra were recorded on a Bruker CXP-300 FT NMR spectrometer operating in the pulsed Fourier transform mode at $300.07 \mathrm{MHz}$ using a spinning $5 \mathrm{~mm}$ tube. Sodium 2,2-dimethyl-2-silapentane-5sulfonate (DSS) was used as an internal reference $(0.00 \mathrm{ppm})$ in $\mathrm{D}_{2} \mathrm{O}$ solution. Deuterated dimethyl sulfoxide $(2.49 \mathrm{ppm}$ from DSS) was used as a reference in DMSO- $d_{6}$ solution. The $\mathrm{pD}$ values given are the actual $\mathrm{pH}$ meter readings and were not corrected for deuterium isotope effects at the glass electrode. Adjustment of $\mathrm{pD}$ was made by adding either a $\mathrm{NaOD}$ or $\mathrm{DCl}$ solution. Observed NMR signals were assigned to the individual amino acid residue by comparing the chemical shifts of the peptides with those of model compounds and the technique of homonuclear spin decoupling.

\section{RESULTS}

Side Chain Peculiarity of D-Leu in Cyclic Peptides

The D-leucyl $\delta$-methyl proton resonances $(0.67-0.75 \mathrm{ppm})$ of 2 and those $(0.69-0.78$ ppm) of 3 in DMSO- $d_{6}$ solution are located in a magnetic field higher than those of Boc-DLeu-OH (0.82-0.88 ppm), Boc-D-Leu-L-His$\mathrm{OCH}_{3} \quad(0.79-0.83 \mathrm{ppm})$, and another random-coiled peptide $(0.85-0.89 \mathrm{ppm}) .^{11}$ The same tendency can also be observed in a $\mathrm{D}_{2} \mathrm{O}$ solution. The D-leucyl $\delta$-methyl protons of 2 and 3 have chemical shifts at $0.76 \mathrm{ppm}$ at pD 5.48 and $0.77 \mathrm{ppm}$ at pD 5.53, respectively. In contrast, random-coiled peptides have chemical shifts at ca. $0.9 \mathrm{ppm}^{12}$ and Boc-DLeu-L-His- $\mathrm{OCH}_{3}$ has $c a$. $0.85 \mathrm{ppm}$.

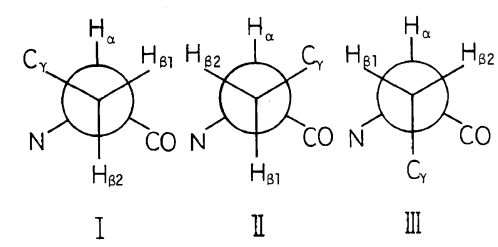

Figure 1. Three staggered rotamers possible for the histidyl residue.

\section{Conformation of Histidyl Side Chains in $\mathrm{D}_{2} \mathrm{O}$}

The rotamer populations of the histidyl side chains of 2 and 3 were evaluated from the $\mathrm{H}-$ $\mathrm{C}^{\alpha}-\mathrm{C}^{\beta}-\mathrm{H}$ protons coupling constants $\left(J_{\alpha \beta}\right)$ in $\mathrm{D}_{2} \mathrm{O}$ solution. We have assumed here that the $J_{\alpha \beta}$ values are weighted averages of different conformations in 'a fast equilibrium and that distribution is restricted to the three staggered rotamers in Figure 1. It was also assumed that the gauche and trans coupling constants can be represented by the constant values $J_{\mathrm{g}}$ and $J_{\mathrm{t}}$, respectively. $J_{\mathrm{g}}$ and $J_{\mathrm{t}}$ were calculated to be $3.2 \mathrm{~Hz}$ and $12.4 \mathrm{~Hz}$, from the following 
Karplus-like equation 1 proposed by Kopple et al. ${ }^{13}$

$$
J_{\alpha \beta}=11.0 \cos ^{2} \theta-1.4 \cos \theta+1.6 \sin ^{2} \theta
$$

where $\theta$ denotes the dihedral angle of $\mathrm{H}-\mathrm{C}^{\alpha}-$ $\mathrm{C}^{\beta}-\mathrm{H}$ planes. The populations of the three rotamers $\left(\mathrm{P}_{\mathrm{I}}, \mathrm{P}_{\mathrm{II}}, \mathrm{P}_{\mathrm{III}}\right)$ can be estimated from the following equations proposed by Pachler, ${ }^{14}$

$$
\begin{aligned}
\mathrm{P}_{\mathrm{I}} & =\left(J_{\alpha \beta 2}-J_{\mathrm{g}}\right) /\left(J_{\mathrm{t}}-J_{\mathrm{g}}\right)=\left(J_{\alpha \beta 2}-3.2\right) / 9.2 \\
\mathrm{P}_{\mathrm{II}} & =\left(J_{\alpha \beta 1}-J_{\mathrm{g}}\right) /\left(J_{\mathrm{t}}-J_{\mathrm{g}}\right)=\left(J_{\alpha \beta 1}-3.2\right) / 9.2 \\
\mathrm{P}_{\mathrm{III}} & =1-\mathrm{P}_{\mathrm{I}}-\mathrm{P}_{\mathrm{II}}
\end{aligned}
$$

where $J_{\alpha \beta 1}$ and $J_{\alpha \beta 2}$ denote the $\mathrm{H}-\mathrm{C}^{\alpha}-\mathrm{C}^{\beta}-\mathrm{H}_{\beta 1}$ and the $\mathrm{H}-\mathrm{C}^{\alpha}-\mathrm{C}^{\beta}-\mathrm{H}_{\beta 2}$ protons coupling constants, respectively. $\mathrm{P}_{\mathrm{I}}, \mathrm{P}_{\mathrm{II}}$ and $\mathrm{P}_{\text {III }}$ were determined from eq $2-4$, using the experimental values of $J_{\alpha \beta 1}$ and $J_{\alpha \beta 2}$, assuming that the resonance at higher field is that of $\mathrm{H}_{\beta 2} \cdot{ }^{15}$ The results obtained for $\mathbf{2}$ are summarized in Table I. The rotamer I was found to be predominant; $\mathrm{P}_{\mathrm{I}}$ is 0.96 at $\mathrm{pD} 3.62$ and 0.91 at $\mathrm{pD}$ 5.48. In the case of 3, correct values of $J_{\alpha \beta 1}$ and $J_{\alpha \beta 2}$ could not be obtained owing to the poor resolution of the ${ }^{1} \mathrm{H}$ NMR spectrum under the experimental conditions. Other values of $J_{\mathrm{g}}$ and $J_{\mathrm{t}}$ proposed by Pachler are 2.6 and $13.6 \mathrm{~Hz}$, respectively and differ somewhat from those estimated from the Kopple's equation $1 .{ }^{14}$ The $\mathrm{P}_{\mathrm{I}}$ values calculated using them are 0.85 at $\mathrm{pD} 3.62$ and 0.82 at $\mathrm{pD}$ 5.48. Although these $\mathrm{P}_{\mathrm{I}}$ values are a little less than those shown in Table $\mathrm{I}$, the tendency for the rotamer I to be predominant persists. As pointed out by Kopple et al., ${ }^{13}$ the use of eq 1 is more appropriate when the rotational freedom of side chains is limited. Although the conformation of the histidyl side chain was analyzed on the assumption of the fast equilibrium between different conformations, the histidyl side chain takes on an almost unique conformation (rotamer I). Consequently Kopple's coupling constant (3.2 and $12.4 \mathrm{~Hz}$ ) seems more preferable in the present study.
Table I. Rotamer populations of histidyl side chain of $c y c l o\left(\mathrm{~L}-\mathrm{Ser}(O \text {-Bzl)-D-Leu-L-His })_{2}\right.$ in $\mathrm{D}_{2} \mathrm{O}$

\begin{tabular}{cccc}
\hline $\mathrm{pD}$ & $\mathrm{P}_{\mathrm{I}}$ & $\mathrm{P}_{\mathrm{II}}$ & $\mathrm{P}_{\mathrm{III}}$ \\
\hline 3.62 & 0.96 & 0.01 & 0.03 \\
5.48 & 0.91 & 0.04 & 0.05 \\
\hline
\end{tabular}

\section{Temperature Dependence of Chemical Shifts in DMSO-d}

The chemical shifts $(\delta)$ and their temperature coefficients $(\mathrm{d} \delta / \mathrm{d} T)$ of the peptide bond protons of $\mathbf{2}$ and $\mathbf{3}$ were measured in a DMSO$d_{6}$ solution as shown in Table II, to determine which protons are shielded from the solvent. The data on $\mathbf{4}$ are shown for comparison. A correct value for the chemical shift was not obtained for $\mathrm{L}-\operatorname{Ser}(O$-Bzl $)$ peptide proton of 2 owing to the overlapping of this signal with those of the phenyl protons ( $c a .7 .3 \mathrm{ppm}$ ). However, it is apparent that the chemical shift of this proton is situated in a much higher field than that of an ordinary random-coiled peptide $(c a .8 .0 \mathrm{ppm})^{11}$ or that of $4(8.09 \mathrm{ppm})$ as shown in Table II. The chemical shift of the seryl peptide proton of $\mathbf{3}$ is also situated in a higher field $(7.22 \mathrm{ppm})$. It should be noted moreover that this seryl peptide proton has a considerably small temperature coefficient $\left(-\mathrm{d} \delta / \mathrm{d} T ; 0.0013 \mathrm{ppm} \mathrm{deg}^{-1}\right)$, compared to the others in 2, 3 and $4(0.0030-0.0055 \mathrm{ppm}$ $\left.\operatorname{deg}^{-1}\right)$. In the case of 4 , none of the peptide protons showed higher-field chemical shifts or small temperature coefficients.

\section{Torsion Angle $\phi$ of Cyclic Peptide 3 in DMSO- $d_{6}$}

The observed $\mathrm{H}-\mathrm{N}-\mathrm{C}^{\alpha}-\mathrm{H}$ protons coupling constant $\left(J_{\mathrm{HN} \alpha}\right)$ may possibly be interpreted in terms of a single conformation, since the cyclic peptide $\mathbf{3}$ is considered to have a fairly rigid skeleton conformation. We calculated the dihedral angle $\left(\theta^{\prime}\right)$ of $\mathrm{H}-\mathrm{N}-\mathrm{C}^{\alpha}-\mathrm{H}$ planes of $\mathbf{3}$, using the experimental $J_{\mathrm{HN} \alpha}$ value according to the Karplus-like equation 5 proposed by Ramachandran et al. ${ }^{16}$ 
Table II. Peptide proton resonances of cyclic peptides in DMSO- $d_{6}$

\begin{tabular}{|c|c|c|c|c|c|c|c|c|}
\hline & \multicolumn{2}{|c|}{2} & & \multicolumn{2}{|c|}{3} & & \multicolumn{2}{|c|}{4} \\
\hline & $\delta^{\mathrm{a}}$ & $-\mathrm{d} \delta / \mathrm{d} T^{\mathrm{b}}$ & & $\delta^{\mathrm{a}}$ & $-\mathrm{d} \delta / \mathrm{d} T^{\mathrm{b}}$ & & $\delta^{\mathrm{a}}$ & $-\mathrm{d} \delta / \mathrm{d} T^{\mathrm{b}}$ \\
\hline & ppm & ppm deg ${ }^{-1}$ & & ppm & ppm deg $^{-1}$ & & ppm & $\mathrm{ppm} \mathrm{deg}^{-1}$ \\
\hline His & 8.66 & 0.0037 & His & 8.51 & 0.0050 & His & 8.53 & 0.0037 \\
\hline Leu & 8.44 & 0.0049 & Leu & 8.19 & 0.0055 & Gly & 8.30 & 0.0040 \\
\hline $\begin{array}{l}\text { Ser } \\
(O-\mathrm{Bzl})\end{array}$ & $7.2-7.4^{\mathrm{c}}$ & - & Ser & 7.22 & 0.0013 & $\begin{array}{l}\text { Ser } \\
(O-\mathrm{Bzl})\end{array}$ & 8.09 & 0.0030 \\
\hline
\end{tabular}

a Chemical shifts refer to partially deuterated DMSO at $299 \mathrm{~K}$ for 2 and $\mathbf{4}$ and at $295 \mathrm{~K}$ for 3.

b Temperature coefficients in the temperature range, $299-339 \mathrm{~K}$ for 2 and 4 and $295-335 \mathrm{~K}$ for 3.

c A correct value could not be obtained owing to overlapping of this signal with those of the phenyl protons. Consequently, only an approximate values is shown.

Table III. Conformational parameter of the main chain of $c y c l o(\mathrm{~L}-\mathrm{Ser}-\mathrm{D}-\mathrm{Leu}-\mathrm{L}-\mathrm{His})_{2}$ in DMSO- $d_{6}$

\begin{tabular}{|c|c|c|c|}
\hline & $J_{\mathrm{HN} \alpha}{ }^{\mathrm{a}}$ & $\theta^{\prime b}$ & $\phi^{\mathrm{c}}$ \\
\hline & $\mathrm{Hz}$ & deg & $\operatorname{deg}$ \\
\hline His & 7.3 & 148 & -88 \\
\hline Leu & 5.8 & 136 & +76 \\
\hline Ser & 7.3 & 148 & -152 \\
\hline
\end{tabular}

a $\mathrm{H}-\mathrm{N}-\mathrm{C}^{\alpha}-\mathrm{H}$ coupling constant.

b Dihedral angle of $\mathrm{H}-\mathrm{N}-\mathrm{C}^{\alpha}-\mathrm{H}$ planes estimated from $J_{\mathrm{HN} \alpha}$.

c Conventional angle obtained from $\theta^{\prime}$, according to the IUPAC-IUB convention.

$$
J_{\mathrm{HN} \alpha}=7.9 \cos ^{2} \theta^{\prime}-1.5 \cos \theta^{\prime}+1.3 \sin ^{2} \theta^{\prime}
$$

The conventional $\phi$ values were obtained from the $\theta^{\prime}$ values in a manner similar to that in the case of $1 .^{6}$ The results for 3 are indicated in Table III.

Another Karplus-like equation 6 was proposed by Bystrov et al. for the relation between $J_{\mathrm{HN} \alpha}$ and $\theta^{\prime},{ }^{17}$

$$
J_{\mathrm{HN} \alpha}=9.0 \cos ^{2} \theta^{\prime}-1.0 \cos \theta^{\prime}+0.4 \sin ^{2} \theta^{\prime}
$$

where $J_{\mathrm{HN} \alpha}$ was corrected for the substituent electronegativity assuming the Pauling scale of electronegativities. The $\theta^{\prime}$ values estimated from eq 6 are $147 \mathrm{deg}$ for His, $137 \mathrm{deg}$ for DLeu, and $147 \mathrm{deg}$ for Ser, which are nearly equal to those shown in Table III.

\section{DISCUSSION}

The results about the chemical shifts of Dleucyl $\delta$-methyl protons of $\mathbf{2}$ and $\mathbf{3}$ seem to be associated with the conformation of the imidazolyl ring situating near D-Leu. That is to say, the higher-field chemical shifts of those protons seem due to the local diamagnetic field caused by the imidazolyl ring current. This speculation is supported by the findings shown in Table I that the population of the rotamer I is significantly high for $2\left(\mathrm{P}_{1}>0.9\right)$ and by the fact that the torsion angle $\chi_{2}$ is apt to be around $90 \mathrm{deg}$ in the case of the histidyl side chain. ${ }^{15}$ That is, these findings mean that the histidyl imidazolyl ring of $\mathbf{2}$ is very likely face toward the adjacent D-leucyl side chain. This suggests that the histidyl imidazole is not folded on the cyclic molecular plane but extends outward. It is generally recognized that the aromatic side chain is frequently folded in cyclic dipeptides, a rare occurrence in larger cyclic peptides, ${ }^{18}$ and that histidyl imidazole tends to orient itself toward the adjacent residue on the $\mathrm{N}$ side. ${ }^{15}$ These tendencies are consistent with our results. It is noteworthy, however, that $P_{I}$ is much larger than that reported thus far. For instance, in the case of cyclo(Gly-Gly-L-HisGly-Gly-L-Tyr), ${ }^{7} \quad$ cyclo(Gly-L-His-Gly-GlyGly-Gly) ${ }^{7}$ and other histidine-containing linear peptides, ${ }^{15} \mathrm{P}_{\mathrm{I}}$ does not exceed 0.6. 
Perhaps the present study is the first instance in which such a high population for rotamer I has been observed. This may be ascribed to the conformational rigidity of the main chain of 2 , which should be due to the freezing of internal rotation by two intramolecular hydrogen bonds and bulky side chains. Similar findings were also obtained for $\mathbf{1}$, as described in the previous paper. ${ }^{6}$ In the case of $c y c l o(\mathrm{D}-\mathrm{Leu}-\mathrm{L}-$ Glu-L-His-D-Leu-L-Glu-L-His) (5) which has L-His-D-Leu sequences instead of D-Leu-L-His ones, the chemical shifts of the D-leucyl $\delta$ methyl protons are located at $c a .0 .9 \mathrm{ppm}$ both in DMSO- $d_{6}$ and in $\mathrm{D}_{2} \mathrm{O} .{ }^{19}$ These chemical shifts are not very different from those in random-coiled peptides, ${ }^{11,12}$ suggesting that the D-leucyl side chain is not situated in the shielding region of the imidazole in $\mathbf{5}$.

Jäckle et al. found a correlation between the chemical shift difference $(\Delta \beta)$ in histidyl $\beta$ methylene protons and rotamer populations and showed $\Delta \beta$ to be linearly related to rotamer populations. ${ }^{15}$ According to this correlation, it can be said qualitatively that the higher $\mathrm{P}_{\mathrm{I}}$ is, the larger is $\Delta \beta$. The large values of $\mathrm{P}_{\mathrm{I}}$ and $\Delta \beta$ (ca. $0.4 \mathrm{ppm}$ ) for 2 are compatible with the correlation described above. The same tendency can be observed for $1 .^{6} \Delta \beta$ is small in the case of cyclo(Gly-Gly-L-His-GlyGly-L-Tyr) (0.12 ppm) and cyclo(Gly-L-HisGly-Gly-Gly-Gly) (0.1 ppm), which is consistent with the smaller values of $\mathrm{P}_{\mathrm{I}}(<0.6){ }^{7}$ Also in the case of $5, \Delta \beta$ is small $(<0.2 \mathrm{ppm}) .{ }^{19}$ $\mathrm{P}_{\mathrm{I}}$ of 5 is probably not so large.

As described in the Results section, the $\mathrm{L}$-Ser peptide proton in $\mathbf{3}$ has a temperature coefficient considerably lower than the others in $\mathbf{2}$, 3 and 4. The chemical shifts of the L-Ser peptide proton in 3 and the L-Ser $(O$-Bzl) peptide proton in $\mathbf{2}$ are located in a much higher field than that of a random-coiled peptide. ${ }^{11} \mathrm{It}$ is generally known that both small temperature coefficients and higher-field chemical shifts of peptide protons are characteristic of transannular hydrogen bonds in cyclic peptides. $^{20-24}$ It is thus concluded that both 2 and
3 form transannular hydrogen bonds between two $\mathrm{L}-\mathrm{Ser}(O-\mathrm{Bzl})$ residues and between two $\mathrm{L}-$ Ser residues, respectively. This means that both 2 and 3 have $\beta$-turns at D-Leu-L-His. 4, which had Gly-L-His instead of D-Leu-L-His, does not form $\beta$-turns. The D-Leu-L-His sequence is quite likely to take on a greater degree of stability by forming a $\beta$-turn than other kinds of sequence. This is consistent with the data in the previous study. ${ }^{6}$ The $\delta$ and $-\mathrm{d} \delta / \mathrm{d} T$ values of L-His (8.66 ppm, 0.0037 ppm $\mathrm{deg}^{-1}$ ) and D-Leu (8.44 ppm, 0.0049 ppm deg $\left.{ }^{-1}\right)$ in 2 are very similar to those $(8.65$ ppm, 0.0033 ppm deg ${ }^{-1} ; 8.43$ ppm, 0.0043 ppm deg ${ }^{-1}$ ) in $1 .^{6}$ Thus, the main chain conformation of 2 resembles that of $\mathbf{1}$. The $\delta$ and $-\mathrm{d} \delta / \mathrm{d} T$ values of $\mathrm{L}-\mathrm{His}$ (8.51 ppm, 0.0050 ppm $\mathrm{deg}^{-1}$ ) and D-Leu (8.19 ppm, 0.0055 ppm deg ${ }^{-1}$ ) in $\mathbf{3}$ differ a little from those in $\mathbf{1}$ and 2, while those of L-Ser (7.22 ppm, 0.0013 ppm $\left.\mathrm{deg}^{-1}\right)$ are close to those of L-Cys $(S$ Acm) (7.43 ppm, 0.0014 ppm $\left.\mathrm{deg}^{-1}\right){ }^{6}$ The main chain conformation of $\mathbf{3}$ appears somewhat different from those of $\mathbf{1}$ and $\mathbf{2}$, although all these cyclic peptides have similar types of $\beta$-turn.

The major conformation of $\mathbf{5}$ is asymmetric in DMSO- $d_{6}$ on the NMR time scale and has only one $\beta$-turn at either of two D-Leu-L-Glu sequences. ${ }^{19}$ This is of particular interest in connection with our cyclic peptides in that the reverse sequence, L-His-D-Leu, does not induce a $\beta$-turn. The characteristic in common in 5 and our peptides is that $\mathrm{D} \rightarrow \mathrm{L}$ sequences induce $\beta$-turns, while 5 has only one $\beta$-turn per molecule.

The type of $\beta$-turn could be estimated by analyzing $\phi$ obtained from $\theta^{\prime}$. It is considered that $\theta^{\prime}$ represents an approximate value, since there is some uncertainty in the measurement of $J_{\mathrm{HN} \alpha}$. Thus $\phi$ is also an approximate value. The error in $\theta^{\prime}$ should be about $\pm 10 \mathrm{deg} .^{25,26}$ The $\phi$ values of $\mathbf{3}$ shown in Table III are, as a whole, similar to those of $1{ }^{6}$ indicating conformational similarity in $\mathbf{1}$ and 3. By comparing $\phi$ in Table III with the conformational 
map prepared by Venkatachalam, ${ }^{27}$ it is evident that 3 has the Type II' $^{\prime} \beta$-turn. Accordingly, the most probable $\phi$ values in Type II' $\beta$-turn are $+60 \mathrm{deg}\left(\phi_{2}\right)$ and $-80 \mathrm{deg}$ $\left(\phi_{3}\right) .{ }^{27}$ Here, the $\phi$ values are represented according to the IUPAC-IUB convention, ${ }^{28}$ and thus differ from those used by Venkatachalam. In the case of 3, the $\phi$ values for $\mathrm{D}-\mathrm{Leu}$ and $\mathrm{L}-\mathrm{His}$ are $+76 \mathrm{deg}$ and -88 $\mathrm{deg}$, respectively. These values as well as those of $\mathbf{1}$ are close to the calculated values given above. Although no $\phi$ values were obtained for 2, a similar type of $\beta$-turn is apparently formed. Other types of $\beta$-turns may be formed at the other sequences such as L-Ser-D-Leu (Type II), L-His-L-Ser (Type I). ${ }^{27}$ However, that all the cyclic peptides studied have $\beta$-turns at D-Leu-L-His regardless of the kind of the other residue implies that this $\beta$-turn is significantly more stable than others.

Giessner-Prettre et al. calculated the shift of the proton resonance due to the effects of the ring current. ${ }^{29}$ The CPK molecular model constructed on the basis of the results obtained in the present study shows that the distance between the D-Leu $\gamma$-carbon and center of the imidazolyl ring is $c a$. $5 \AA$. The observed upfield shifts of D-leucyl $\delta$-methyl protons are $0.1-0.2$ ppm. When comparing the observed shifts with those calculated, it seems sufficiently reasonable to say that the ring current is responsible for the upfield shifts. Similar conclusion can be drawn for $\mathbf{1}$.

The present study has shown that the rotamer I for the histidyl side chain is very stable $\left(P_{I}>0.9\right)$. This is the first instance in which such a high population in histidine-containing peptides has been observed. It was also found that D-Leu-L-His sequence has a tendency to induce fairly stable $\beta$-turns (Type II').

\section{REFERENCES}

1. J. C. Sheehan arid D. N. McGregor, J. Am. Chem. Soc., 84, 3000 (1962).

2. K. D. Kopple and D. E. Nitecki, J. Am. Chem. Soc.,
84, 4457 (1962)

3. K. D. Kopple, R. R. Jarabak, and P. L. Bhatia, Biochemistry, 2, 958 (1963).

4. Y. Imanishi, M. Tanihara, T. Sugihara, and T. Higashimura, Biopolymers, 16, 2203 (1977).

5. M. Tanihara, Y. Imanishi, and T. Higashimura, Biopolymers, 16, 2217 (1977).

6. M. Kodaka, T. Shimizu, and M. Hatano, Bull. Chem. Soc. Jpn., 56, 1181 (1983).

7. K. D. Kopple, M. Ohnishi, and A. Go, Biochemistry, 8, 4087 (1969).

8. M. Kodaka, T. Shimizu, and M. Hatano, Bull. Chem. Soc. Jpn., 56, 523 (1983).

9. N. Izumiya, T. Kato, M. Ohno, and H. Aoyagi, "Peptide Gosei," Maruzen, Tokyo, 1975, pp 229230.

10. G. D. Fasman and E. R. Blout, J. Am. Chem. Soc., 82, 2262 (1960).

11. A. Bundi, C. Grathwohl, J. Hochmann, R. M. Keller, G. Wagner, and K. Wüthrich, J. Magn. Reson., 18, 191 (1975).

12. C. C. McDonald and W. D. Phillips, J. Am. Chem. Soc., 91, 1513 (1969).

13. K. D. Kopple, G. R. Wiley, and R. Tauke, Biopolymers, 12, 627 (1973).

14. K. G. R. Pachler, Spectrochim. Acta, 20, 581 (1964).

15. H. Jäckle and P. L. Luisi, Biopolymers, 20, 65 (1981).

16. G. N. Ramachandran, R. Chandrasekaran, and K. D. Kopple, Biopolymers, 10, 2113 (1971).

17. V. F. Bystrov, V. T. Ivanov, S. L. Portnova, T. A. Balashova, and Yu. A. Ovchinnikov, Tetrahedron, 29, 873 (1973).

18. T. Sugihara, Y. Imanishi, T. Higashimura, and Y. Shimonishi, J. Org. Chem., 41, 2584 (1976).

19. M. Tanihara and Y. Imanishi, Polym. J., 15, 509 (1983).

20. K. D. Kopple, M. Ohnishi, and A. Go, J. Am. Chem. Soc., 91, 4264 (1969).

21. K. D. Kopple, T. J. Schamper, and A. Go, J. Am. Chem. Soc., 96, 2597 (1974).

22. L. G. Pease, C. M. Deber, and E. R. Blout, J. Am. Chem. Soc., 96, 258 (1973).

23. R. Schwyzer, C. Grathwohl, J. P. Meraldi, A. TunKyi, R. Vogel, and K. Wüthrich, Helv. Chim. Acta, 55, 2545 (1972).

24. S. L. Portnova, V. V. Shilin, T. A. Balashova, J. Biernat, V. F. Bystrov, V. T. Ivanov, and Yu. A. Ovchinnikov, Tetrahedron Lett., 1971, 3085.

25. D. W. Hughes and C. M. Deber, Biopolymers, 21, 169 (1982).

26. K. D. Kopple, Biopolymers, 10, 1139 (1971).

27. C. M. Venkatachalam, Biopolymers, 6, 1425 (1968).

28. "IUPAC-IUB Commission on Biochemical Nomenclature," Biochemistry, 9, 3471 (1970).

29. C. Giessner-Prettre and B. Pullman, J. Theor. Biol., 31, 287 (1971). 